\title{
Still Minding the Gap? Reflecting on Transitions between Concepts of Information in Varied Domains
}

\author{
David Bawden * ${ }^{(D)}$ and Lyn Robinson \\ Centre for Information Science, City, University of London, Northampton Square, London EC1V 0HB, UK; \\ 1.robinson@city.ac.uk \\ * Correspondence: d.bawden@city.ac.uk
}

Received: 28 December 2019; Accepted: 25 January 2020; Published: 29 January 2020

\begin{abstract}
This conceptual paper, a contribution to the tenth anniversary Special Issue of Information, gives a cross-disciplinary review of general and unified theories of information. A selective literature review is used to update a 2013 article on bridging the gaps between conceptions of information in different domains, including material from the physical and biological sciences, from the humanities and social sciences including library and information science, and from philosophy. A variety of approaches and theories are reviewed, including those of Brenner, Brier, Burgin and $\mathrm{Wu}, \mathrm{Capurro}$, Cárdenas-García and Ireland, Hidalgo, Hofkirchner, Kolchinsky and Wolpert, Floridi, Mingers and Standing, Popper, and Stonier. The gaps between disciplinary views of information remain, although there has been progress, and increasing interest, in bridging them. The solution is likely to be either a general theory of sufficient flexibility to cope with multiple meanings of information, or multiple and distinct theories for different domains, but with a complementary nature, and ideally boundary spanning concepts.
\end{abstract}

Keywords: information theory; entropy; review; general theories of information; unified theories of information; philosophy of information; library and information science

\section{Introduction}

'Information is in everything. It has become the foremost concept in biology, physics, economics, engineering, philosophy, decision-making, methodology of science, artificial intelligence, computer science, etc. Naturally, in different domains, information appeared in different forms and shapes, which depend on the context and environment ... Due to such a diversity of information forms and shapes, researchers have built many specialized information theories trying to reflect important aspects of information' [1] (p. 1).

While we might consider this view, expressed by Burgin and Hofkircher, to be somewhat exaggerated - we doubt if the average physicist or philosopher, even today, necessarily considers information their most important concept-there is much truth in their summarisation. The multiplicity of information theories, and of conceptions of information, leads to discontinuities and incompatibilities, to gaps.

In a book chapter published six years ago [2], based on an earlier conference presentation [3], we examined the usage of the term 'information' in various subjects and domains, considering, in particular, these gaps, or discontinuities in understanding, between them. This, we hoped, would shed light on the perennial question of whether there is some underlying sameness in the nature of information as understood in different domains; whether it is, in some sense, the same thing. The alternative, of course, is that there is little or no underlying sameness; rather the situation is confused by the use of the same English word-information-for things and processes which have only a superficial, or a very general, similarity [4]. 
In that chapter we examined five domains: information and communications technology; information physics; information biology; social information; and philosophy of information. Particular attention was given to the perspective of library and information science (LIS), as this was the focus of the volume in which the chapter appeared. We argued that this focus was appropriate, as LIS is the domain which, above all others, focuses on information, and whose contributions are somewhat underrated outside the discipline; this focus will be maintained in the present article. Three specific conceptions for gap-bridging by providing an account of information relevant across all domains were given: those due Stonier, Bates, and Floridi, respectively.

Our conclusions to this chapter were that it is worth trying to bridge the gaps, and that attempts to do so have provided valuable insights. Not through the finding of simple and direct equivalences, but rather through the identification of more subtle insights, perhaps through the use of boundary spanning concepts such as complexity and entropy, or through the generation of entirely new conceptions. The study of gap-bridging has often been equated with the construction of unified, or general, theories of information, generally requiring a single definitive answer to the question 'what is information?'. However, such a grand theory may not be necessary, and indeed may not be feasible [5-7]. We will consider gap-bridging ideas both within and without general theories.

In this paper, our intention is to consider developments in the six years since 'Mind the Gap' was written, and to extend the discussion to include a wider variety of theories and conceptualizations beyond those mentioned in the original paper, and hence to assess whether we are any nearer to an understanding of the sameness of information across domains. This analysis is based on a selective literature review, with materials from bibliographic databases (Web of Science and Library and Information Science and Technology Abstracts), from Google Scholar, and from reference and citation following. In covering such a broad area in a relatively short paper, this will necessarily be an overview, limited in the degree of detail in which each aspect can be discussed.

This paper is intended as a contribution to the debate about the nature of information; a debate which is long-running, as Capurro points out [8], but which appears to be gaining in intensity and significance. However, since our focus is on gap-bridging proposals, and there is a substantial literature relating to these, we will not address the question of the nature of information, nor of the relations between data, information, knowledge, and similar entities, except where they form part of a gap-bridging theory,

An initial presentation of developments since 2013 is followed by a discussion of gap-bridging concepts, including the three in the original paper and others which have emerged, or taken on an importance, since its publication. The intention throughout is to update the original 'Mind the Gap' chapter without repeating its arguments in any detail.

\section{The Information Concept in Different Domains}

This part of the paper is structured in a similar, though simpler, way to that of the original chapter: developments in science and technology; developments in humanities and social sciences, including library and information science; and developments in philosophy of information.

\subsection{Information in Science and Technology}

The concept of objective information began within communication technology [9], was introduced into the physical and biological sciences through Brillouin and Schrödinger, and continues to extend its reach; see, for example, the contributions to the volumes edited by Davies and Gregersen [10] and by Durham and Rickes [11].

Interest in, and use of, information concepts, and Shannon's information theory in particular, within the physical sciences have continued to increase and have been reviewed from the perspective of gap-bridging [12-15].

The increasing acceptance of information as a physical quantity is indicated by the importance given to it in an article on the next hundred years in physics by Nobel laureate Frank Wilczek [16], 
who predicts that fundamental action principles, and thus the laws of physics, will be interpreted as statements about information and its transformation.

He notes that there has been a unification fusing the physical quantity entropy and the conceptual quantity information, and argues for the necessity for a strong formal connection between entropy and action. This information-entropy relationship has been, and remains, at the heart of discussions of information physics. In an influential review article, Parrondo, Horowitz and Sagawa [17] analyse the introduction of information into thermodynamics, suggesting that to reconcile the information/entropy relation with classical thermodynamics, which makes no mention of information, requires two things: restating thermodynamic laws to incorporate information explicitly, and clarifying the physical nature of information, so that it enters thermodynamic laws as a physical entity, not an abstraction. These authors suggest that we are still several steps away from a complete understanding of the physical nature of information; in particular, we need a general physical theory of information to explain how the macroscopic world and the subjectivity of entropy emerge from statistical mechanics. An example of continuing studies of this kind is given by Müller [18], who shows how the entropy of a gas is partly comprised of information about the location of the molecules. The information/entropy relationship in complex systems has been analysed in detail in a book chapter [19], and set in context in a recent review article [20].

The information/entropy relationship, of course, relates to the second law of thermodynamics. An example of the continuing penetration of information concepts into physics is given in the demonstration that the third law of thermodynamics, generally expressed as the impossibility of reaching absolute zero, is related to the maximum speed with which information can be erased [21]. There has also been continuing interest in reconstructing the formalism of quantum theory in information terms [22,23].

Information concepts are playing an ever-increasing role in our understanding of the biological realm, conceptually as well as through the techniques of bioinformatics. This follows Schrödinger's initial insight that information may play a crucial role as a fundamental feature of living systems and may provide a link between the living and non-living worlds [24]; for reviews marking the 75th anniversary of the publication of Schrödinger's book, see $[25,26]$. Later insights included Gatlin's introduction of information theory concepts into biology [27], and Marijuan's conclusion that living existence is 'informational', that there is an 'invisible hand' of information in biology [28]. Davies provides an accessible recent review of progress towards a general theory of biological information [29].

The contributions of Thomas Sebeok (1920-2001) to the development of biosemiotics, or semiotic biology, are being more widely recognised. This takes a very different view of information in biology to the more common invocation of Shannon's information formalism and focuses on communication, signs, and meaning within all living systems, thereby providing 'a bridge between biology, philosophy, linguistics and the communication sciences' [30]; see also [31-33].

Another means of bringing the concepts of information, meaning, and complexity into biology is the concept of 'code biology', promoted particularly by Marcello Barbieri, the analysis of codes in living systems at various levels from the genetic code to codes of culture [34,35]. An anonymous reviewer has suggested that the idea of mechanism in code biology may reasonably be compared to the idea of maker's knowledge in Floridi's Philosophy of Information; an intriguing gap-bridging analogy.

Lacking at present a generally accepted over-arching theory, we observe numerous studies expanding understanding of information concepts in various areas of biology. To give a flavour of these, we can mention Integrated Information Theory, which studies consciousness as a function of information processing at different levels [36]: the idea that spiders use their webs as an external information-storing memory device [37], and the realization that biological cells perform a kind of optimal processing during development [38].

Of significance to both the physical and biological sciences, and of particular relevance to this review, is a new definition of semantic information, intended to complement Shannon's syntactic information and defined as syntactic information that a physical system has about its environment, which is causally necessary for the system to maintain its own existence [39]. It is notable that, although 
these authors note that a definition of semantic information is of interest, inter alia, to philosophy, they do not cite any of the philosophical theories discussed later; a symptom, perhaps, of a systemic problem of this topic, to be discussed in the conclusions. An alternative definition of information, rooted in semiotics and related to many other conceptions, has been proposed by Cárdenas-García and Ireland [40].

Although there is continuing, and indeed increasing, interest in the study of information as a component of the physical world and as intrinsic to the biological realm, the information-related theories advanced within this domain do not generally extend to the human and social worlds. For such gap-bridging theories, we must current look to philosophy, as discussed below.

\subsection{Information in Humanities and Social Sciences}

In the area of humanities and social sciences (HSS), qualitative analyses of the nature of information, without being developed into fuller theories, continue, recent examples being due to Bosancic and Matijevic [41], Capurro [8] and Chapman [42]. Janich, answering the question 'what is information?' in a book with that title, argues for a view of information as a cultural artefact, rooted in philosophy of language, and denying any real relation between Shannon information and thermodynamic entropy [43]. Clearly, such a viewpoint will not lend itself to development of any kind of integrated theory of information, nor will the increasingly prevalent use of information, entropy, and complexity, within literature (see, for example, the reviews by Hayles [44], and by Groes [45], although they are a further reminder of the increasing reach of these ideas). This increasing reach may be seen as an outworking of Luciano Floridi's The Fourth Revolution [46], as the centrality of information, and information technologies in our society is increasingly reflected in art and literature, and explicitly recognised in the work of creative artists; see, for example, the recent study by Gorichanaz [47].

The same limitations may perhaps also be said to apply to two very significant contributions from HSS, those of Brier and of Capurro, which emphasise hermeneutics, communication, and meaning, and may therefore be categorised as humanist, or neo-humanist, approaches.

Søren Brier's cybersemiotics, a transdisciplinary framework, where signs, meaning, and interpretation are fundamental, and where, to quote the title of Brier's best known text 'information is not enough' [48-51]. Based on Pierce's semiotics, and to a degree overlapping with the biosemiotics approach noted above, it focuses on signs producing meaning in biological systems, including the human and the social, and eschews a purely logical and mathematical foundation. It has been highly influential, Brenner denoting it as 'one of the most significant and original recent contributions to information theory' [52] (p. 154). It is not, however, easy to see how it bridges the gap to the physical world, although Brier's arguments are cogent in pointing out the lacuna between some objective logical formulations of information and the richness of lived meaningful experience. Mingers and Standing provide a somewhat similar theory of information based on signs and messages, but one which allows that information exists in the absence of observers/recipients and also includes the Floridi-like requirement that information be true or correct; hence the theory is denoted as one of objective and veridical information [53].

Capurro recommends a concept of information that connects human and non-human 'angeletic' phenomena, without attempting to ignore their differences, noting that this has some commonality with Brier's cybersemiotics [54]; for a comparison with other information theories, see [55].

Although systems such as those of Brier and of Capurro are likely to lead in themselves to unified theories, it may be that they will be complementary to more objective schemes, the gaps being bridged through this complementarity, as is implied by Brier [51].

Finally, in this section may be mentioned the work of Hidalgo [56], who gives a broad qualitative analysis of economic, social, and business issues in terms of Shannon's information, complexity, and information entropy. 


\subsection{Philosophy of Information}

There has been continued interest in the development of general theories, or unified theories, of information, bridging the gaps between the ideas of information in different domains. Brenner gives a helpful comparison of several [52], and later developments are briefly reviewed below.

In the original 'Mind the Gap' paper, we identified several such philosophical contributions to the concept of information, mentioning three in particular: the attempts by various philosophers, most notably Fred Dretske, to develop Shannon's information theory to include meaning and knowledge; Karl Popper's Three Worlds ontology, and particularly his World Three of objective knowledge; and Luciano Floridi's Philosophy of Information.

The first of these is generally considered to have met with little success. Rather, the ideas advanced have been incorporated into more recent and more extensive philosophical approaches, most notably that of Floridi, who develops his analysis of information on the basis of Shannon's theory and extends it to meaningful information and to knowledge. We may conclude that it is this approach which will take forward the ideas pioneered by Dretske and others.

The ontology put forward by Popper [57], once heralded as a theory of information suitable to form a foundation for information science [58], and by implication other social sciences, has generally fallen into disfavour as an unnecessary complication, or even a mystification, of the concept of information. Notturno, himself an advocate of the value of Popper's ideas, wrote that 'most contemporary philosophers regard World 3 as an unfortunate product of Popper's old age: as incoherent, irrelevant and perhaps, if the truth be told, a bit ridiculous ... [but] ... most philosophers who reject Popper's theory of World 3 simply do not understand it' [59] (pp. 139 and 145). While we have argued that a reappraisal of Popper's ontology is overdue and would be worthwhile [55], it remains for the moment out of favour in philosophical circles, although it continues to be referenced within LIS; see, for example, [60].

It is worth noting that Floridi has acknowledged the influence of Popper's idea of World Three of objective knowledge in the development of his Philosophy of Information [61] (p. 95); the point is discussed by Bawden and Robinson, and by Floridi, in a set of essays on Floridi's The Logic of Information [62]. Burgin also notes a relation between his General Theory of Information and Popper's ontology [63] (pp. 58-59 and 551). As with Dretske, therefore, we may see Popper's insights being best carried forward within these more recent and more developed philosophical frameworks.

Floridi's Philosophy of Information (PI) has been developed over a long period and described in numerous publication, encapsulated in his The Philosophy of Information [64], as noted in the original 'Mind the Gap' chapter. The scheme has been considerably extended since then, as set out in Floridi's The Ethics of Information [65] and The Logic of Information [61]; a further volume, the last of a tetralogy, of the politics of information is forthcoming. This is an ambitious 'philosophy for the information age', which is now bearing fruit, as we will note later, in providing detailed analyses of the philosophical and ethical aspects of the developing information society and its enabling digital technologies. It is founded in an integrated theory of information at all levels and has proved the most fruitful of such approaches so far. Core to this is a general definition of information, with information equated to 'well-formed, meaningful, and truthful data', a view which Floridi notes is in accordance with Shannon's formalism. Data are understood as a lack of uniformity, a notable difference or distinction. Information is converted to knowledge through being interrelated. This provides an integrated view, which incorporates various forms of information, including physical, environmental, and biological information, as the information and knowledge created and communicated by Floridi's 'inforgs': humans and other information processing entities.

Floridi emphasises that PI is not intended to provide a single, unified theory of information in all domains, but rather to provide a formal framework for linking and relating the various aspects and manifestations of information, and hence for integrating, though not in a reductionist way, all information-centred disciplines [66]. As an example of its extensibility, Walton has presented a model which extends Floridi's concepts by explicitly integrating evolutionary, static, and dynamic views 
of information, highlighting relations between information in the physical world and information as symbolic content, and has used this to analyse the relation between information, truth, and meaning [67-69].

A somewhat similar approach, bridging gaps through a broad and formal approach, has been taken by Mark Burgin, in his General Theory of Information (GTI) [63,70-72], extended to include an evolutionary perspective [73]; a helpful summary is given by Burgin and Feistel [74]. Developed over several decades, the GTI is a mathematical theory, aiming to incorporate previous approaches, including those of Shannon, Bar-Hillel, Dretske, and others. It aims, as Brenner puts it in a review of Burgin's 2010 book, to 'explain relations between a huge diversity of meanings of the word information, making it possible to unify these understandings' [75] (p. 224). Burgin's GTI offers a parametric definition of information as that which has a capacity to cause changes in a system, so that information may be seen as a form of energy. This concept is used to integrate earlier formal definitions of information from various information theory perspectives into a single mathematical framework with a series of ontological and axiological principles which express what information is, and how it may be measured. This approach may, in principle, encompass all forms of information including the physical, biological, mental, and social, and encompassing syntactic, semantic, and pragmatic information. It recognises the distinction between the two basic classes of structural, or embedded, information, which may be related to physical entropy, and symbolic information, which assigns meaning, and is associated with living creatures [74,76,77]: 'Information constitutes a bridge between lifeless physics and living beings struggling for survival' [74] (p. 141). There is a clear analogy here with Floridi's categories of environmental and semantic information. The GTI also addresses the relation between data, information, and knowledge [78]. From it has been developed a series of multiple taxonomies relating all aspects of information in context, based on a triad of physical world, mental world, and world of structures [79]. Burgin's GTI, though an ambitious and broad formalism, has not as yet been extended in any detail into social and ethical domains, as Floridi's has, but it may be regarded as an alternative general formalism with a similar potential for wide applicability.

Joseph Brenner and $\mathrm{Wu}$ Kun have developed what they consider to be a revolution in philosophy, based on a convergence of the science and philosophy of information, and an 'informational turn' in both science and philosophy, leading to a metaphilosophy with information at its centre [80-82]. This examines the role of information, with both its physical and non-physical components, in complex processes across various domains, using a non-standard logic, Logic in Reality (LIR), for its analyses. LIR is a physical theory, and through it information may be directly related to aspects of the physical and biological worlds $[83,84]$. There is a clear similarity here with Floridi's conception of PI as philosophy [64] for the information age. Some of the similarities and differences are analysed by Brenner and $\mathrm{Wu}[52,82,85]$ and by Floridi [86].

We should also mention a further approach to a theory of information applicable across domains due to Wolfgang Hofkirchner, of whose work Brenner commented that in it 'the concept of a Unified Theory of Information has been developed most completely' [81]. Hofkirchner's aim is to seek a theory, a 'superconcept', which would encompass all the different manifestations of information, including the physical and the nonphysical. This ambitious programme is manifested as a framework based on complex systems theory and emergent properties [87-90], the most elaborate and sophisticated account of information in terms of complexity and emergence; for earlier suggestions of this sort, see [91]. Hokfkirchner's theory, however, seems not to have been developed further, nor applied by others, in recent years.

\section{Bridging the Gaps}

In the original chapter, we identified three significant conceptions of an integrated view of information across domains, due respectively to Tom Stonier, a scholar of science and society, Marcia Bates, a professor of library and information science, and Luciano Floridi, a philosopher and ethicist. 
We now briefly review developments in each of these, without repeating our original analysis, before introducing some new developments.

Stonier proposed a conception of information as integrated across the physical, biological, and mental in three books [92-94] and summarised in two journal articles [95,96]. Information is, for Stonier, most fundamentally a physical entity analogous to matter and to energy, being the capacity to create and maintain organization within a system. He argues that this organizing function of information is expressed in the biological world and then in the human intelligence, and in meaning, expressed in recorded information.

Stonier's views have been highly influential, and his books have together been cited over 1000 times. Morán-Reyes suggests that a framework for LIS could be developed based on Stonier's theory of information, but does not set this idea out in detail [97]. It is fair to say that there has been little explicit development of Stonier's specific proposal, and that his work is held up, rather, as an early example of a unified gap-bridging theory of information.

Bates presented an integrated concept of information, from the physical world through the biological realm to meaning and to human knowledge, starting from the idea that information is the degree of order in any system $[98,99]$. It may be seen, as Bates remarks, as an extension of the ideas of Goontilake [100] and of Madden [101], which considered the relations between information in the biological realm and the human social world of communicable knowledge. Whilst undeniably ambitious and wide in scope, the idea suffers from a plethora of forms of information (Information-1, Information-2, Data-1, Data-2, and Knowledge) without formal definition and without clear demarcation between them. In particular, it remains unclear how the gap between information in the physical realm and in the realm of meaning is bridged. Bates' work has certainly been influential (her two papers have each been cited over 200 times), particularly within library and information science, but it appears that there have been no significant extensions to, or developments of, her ideas.

Floridi's PI, as noted above, is a sophisticated and wide-ranging conception, set out in a considerable number of books and articles; a comprehensive overview is given in a set of monographs $[46,61,64,65]$ and in an accessible short introduction [102]. For critical assessments of his scheme as a gap-bridging programme, and comparisons with others, see [7,103-105].

PI has received a great deal of attention and application in the years since the original 'Mind the Gap' chapter was written. Virtually all of this attention has been focused on applications to human information, to the development of what Floridi terms 'mature information societies', and to the appropriate and ethical use of new technologies: examples are privacy [106], data ethics [107], big data [108], information governance [109], artificial intelligence [110], and the politics of information societies [111].

Floridi's PI has been particularly extensively analysed within the LIS discipline, and indeed proposed as a suitable theoretical foundation for that domain: for overviews, see [62,112], and for examples of individual contributions to the debate, see [104,113-116]. This is the only example of one of the general theories from philosophy being adopted within, and potentially contributed to by, a discipline other than the one in which it was developed. For comparison, Mingers and Standing note that Floridi's PI is rarely referenced in the information systems literature [53] (p. 96).

At its most fundamental level, PI addresses the nature of reality itself, through the philosophical stance of 'informational structural realism', which holds that there is an observer-independent reality, whose ultimate nature is neither physical or mental, but informational, and defined by the interactions between informational entities $[64,117,118]$. Also fundamental to PI is the principle of Levels of Abstraction (LoA), which allows information in any context to considered at different levels $[64,119,120]$; see also Chapman [121] on the advantages of a 'layered' perspective on information, of which Floridi's LoA is one example. There is an interesting analogy between PI, with its concepts of a once-only move to an infosphere populated by inforgs, and Stonier's suggestion that the emergence of machine intelligence presages an evolutionary discontinuity [95]. 
Floridi's approach, therefore, seems well-suited to reconciling concepts of information in different domains, including the physical and the biological; there seems, however, to have been little or no application of Floridi's concepts upstream in the physical and biological realms, certainly not compared to its applications to social and ethical issues. Nonetheless, it seems evident that of the three gap-bridging proposals identified in the original chapter, Floridi's is the one which has been, and remains, particularly actively researched and applied.

\section{Conclusions}

Any gap-bridging proposal for information must address what has come to be known as Capurro's trilemma [5]. This suggests that we must understand the meaning of information in different domains in one of three ways: it has the same meaning in all contexts (univocity); it has one true meaning in a specific context, but may be applied as an analogy in others (analogy); or it may have multiple, equally valid meanings in different contexts (equivocity). Each of these poses different problems for gap-bridging proposals [55]. The first is plainly unhelpful, if not simply incorrect. The second lends itself to overly simple analogies, and the third makes any unified theory impossible, and any gap-bridging impossible.

The literature reviewed in this paper suggests that there are two ways to proceed: via a general theory of sufficient flexibility to cope with multiple meanings of information, as with Floridi's LOA approach, or via distinct theories for different domains, but with a complementary nature and perhaps boundary spanning concepts, as with cybersemiotics and 'angeletics'.

Of the gap-bridging theories reviewed here, Floridi's PI has been more developed towards information society and ethics, with clear applications and impact, while Hofkirschner uses his unified theory to address the problems of sustainable information societies [90]. The approaches of Burgin, and of Brenner and $\mathrm{Wu}$, have been more developed towards links with the physical sciences. There has been little uptake, or comparison, of these frameworks within other disciplines, although Morán-Reyes has given a comparison, albeit limited in detail, of the theories of Stonier, Burgin, and Floridi, from the perspective of LIS [97].

The best way of understanding the relationship between physical entropy and the various formulations of information remains to be determined, as does the debate, originating with Shannon and Wiener, as to whether information should be associated with order or with its opposite. 'Unfortunately,' Joseph Brenner wrote in 2014, 'the link of [philosophical] views to science, while adding a further dimension to the discussion often remains insufficiently elaborated' [52] (p. 137); the same is surely true today.

It is notable that, as mentioned earlier, Kolchinsky and Wolpert's paper [39], introducing a new definition of semantic information for the sciences, cites none of the philosophical theories mentioned here; in general, studies on the information concept within the physical sciences are restricted to their own domains. The various general and unified theories of information have all, in various ways, sought an extension to the physical and biological realms, but none seems fully satisfactory and none has been used in developing theory within the sciences.

The gaps then remain, although there has been progress and increasing interest in bridging them. This need not depress us. The nature of information and the best ways in which we may understand it are surely open questions, which will never be finally solved, but about which much understanding may be gained. If, as Floridi tells us, all open questions are philosophical [122], then we should continue to philosophize, and our hope is that cross-disciplinary reviews such as this may act as a stimulus.

Author Contributions: Conceptualization, D.B. and L.R.; investigation, D.B. and L.R.; writing, D.B and L.R. Both authors have read and agreed to the submitted version of the manuscript. Both authors have read and agreed to the published version of the manuscript.

Funding: This publication has received no funding.

Conflicts of Interest: The authors declare no conflict of interest. 


\section{References}

1. Burgin, M.; Hofkirchner, W. Introduction: Omnipresence of information as the incentive for transdisciplinarity. In Information Studies and the Quest of Transdisciplinarity: Unity through Diversity; Chapter 1; World Scientific: Singapore, 2017. [CrossRef]

2. Robinson, L.; Bawden, D. Mind the gap: Transitions between concepts of information in varied domains. In Theories of Information, Communication and Knowledge: A Multidisciplinary Approach; Ibekwe-SanJuan, F., Dousa, T., Eds.; Springer: Berlin, Germany, 2013; pp. 121-141.

3. Bawden, D. Mind the gap: Transitions between concepts of information in varied domains. In Proceedings of the International Conference on 'Information Ecology and Libraries', Bratislava, Slovakia, 10-12 October 2011; pp. 7-13.

4. Bawden, D. The shifting terminologies of information. Aslib Proc. 2001, 53, 93-98. [CrossRef]

5. Capurro, R.; Fleissner, P.; Hofkirchner, W. Is a unified theory of information feasible? A Trialogue. In The Quest for a Unified Theory of Information, Proceedings of the 2nd International Conference on the Foundations of Information Science; Hofkirchner, W., Ed.; Routledge: Abingdon, UK, 1999; pp. 9-30.

6. Capurro, R.; Hjørland, B. The concept of information. Annu. Rev. Inf. Sci. Technol. 2003, 37, $343-411$. [CrossRef]

7. Furner, J. Philosophy and information studies. Annu. Rev. Inf. Sci. Technol. 2010, 44, 161-200. [CrossRef]

8. Capurro, R. A short note on the history of the concept of information. Information 2010, 10, 305. [CrossRef]

9. Gleick, J. The information: A history, a theory, a flood; Fourth Estate: London, UK, 2011.

10. Davies, P.; Gregersen, N.H. (Eds.) Information and the Nature of Reality: From Physics to Metaphyiscs; Cambridge University Press: Cambridge, UK, 2010.

11. Information and Interaction: Eddington, Wheeler, and the Limits of Knowledge; Durham, I.T.; Rickes, D. (Eds.) Springer: Cham, Switzerland, 2017.

12. Bawden, D.; Robinson, L. "Deep down things": In what ways is information physical, and why does it matter for LIS? Inf. Res. 2013, 18, n3.

13. Bawden, D.; Robinson, L. "A few exciting words": Information and entropy revisited. J. Assoc. Inf. Sci. Technol. 2015, 66, 1965-1987. [CrossRef]

14. Bawden, D.; Robinson, L. "Waiting for Carnot": Information and complexity. J. Assoc. Inf. Sci. Technol. 2015, 66, 2177-2186. [CrossRef]

15. Bawden, D.; Robinson, L.; Siddiqui, T. "Potentialities or possibilities": Towards quantum information science? J. Am. Soc. Inf. Sci. Technol. 2015, 66, 437-449. [CrossRef]

16. Wilczek, F. Physics in 100 years. arXiv 2015, arXiv:1503.07735. [CrossRef]

17. Parrondo, J.M.R.; Horowitz, J.H.; Sagawa, T. Thermodynamics of information. Nat. Phys. 2017, 11, 131-139. [CrossRef]

18. Müller, J.G. Information contained in molecular motion. Entropy 2019, 21, 1052. [CrossRef]

19. Nicolis, G.; Nicolis, C. Complexity, entropy and information. In Foundations of Complex Systems: Emergence, Information and Prediction, 2nd ed.; Chapter 4; World Scientific: Singapore, 2012; pp. 114-148.

20. Preiser, R. Identifying general trends and patterns in complex systems research: An overview of theoretical and practical implications. Syst. Res. Behav. Sci. 2019, 36, 706-714. [CrossRef]

21. Masanes, L.; Oppenheim, J. A general derivation and qualification of the third law of thermodynamics. Nat. Commun. 2017, 8, 14538. [CrossRef] [PubMed]

22. Chiribella, G.; D'Ariano, G.M.; Perinotti, P. Informational derivation of quantum theory. Phys. Rev. A 2011, 84, 012311. [CrossRef]

23. Jaeger, G. Information the reconstruction of quantum physics. Annalen der Physik 2018, 531. [CrossRef]

24. Schrödinger, E. What is Life? The Physical Aspect of the Living Cell; Cambridge University Press: Cambridge, UK, 1944.

25. Gazzaniga, M.S. Following Schrödinger's code: A personal journey. J. Cogni. Neurosci. 2019, 31, $1777-1781$. [CrossRef] [PubMed]

26. Moberg, C. Schrödinger's What is Life: The 75th anniversary of a book that inspired biology. Angewandte Chemie Int. Ed. 2019. [CrossRef]

27. Gatlin, L.L. Information Theory and the Living System; Columbia University Press: New York, NY, USA, 1972. 
28. Marijuan, P.C. Information and life: Towards a biological understanding of informational phenomena. Triple-C 2004, 2, 6-19. [CrossRef]

29. Davies, P. The Demon in the Machine; Allen Lane: London, UK, 2019.

30. Tønnessen, M.; Sharov, A.; Maran, T. Biosemiotics: Making Sense of Nature. LifeScienceToday Blog. 15 September 2016. Available online: http://blogs.springer.com/lst/biosemiotics-making-sense-nature/ (accessed on 28 January 2020).

31. Hoffmeyer, J. Biosemiotics: Towards a new synthesis in biology. Eur. J. Semiot. Stud. 1997, 9, 355-376.

32. Barbieri, M. A short history of biosemiotics. Biosemiotics 2009, 2, 221-245. [CrossRef]

33. Kull, K.; Thomas, A. Sebeok and biology: Building biosemiotics. Cybern. Hum. Knowing 2003, 10, 47-60.

34. Barbieri, M. Code Biology: A New Science of Life; Springer: Cham, Switzerland, 2015.

35. Barbieri, M. What is code biology? Biosystems 2018, 164, 1-10. [CrossRef] [PubMed]

36. Tononi, G.; Boly, M.; Massimini, M.; Koch, C. Integrated information theory: From consciousness to its physical substrate. Nat. Rev. Neurosci. 2016, 17, 450-461. [CrossRef]

37. Japyassu, H.F.; Laland, K.N. Extended spider cognition. Anim. Cognit. 2017, 20, 375-395. [CrossRef] [PubMed]

38. Potkova, M.D.; Tkačik, G.; Bialek, W.; Wieschaus, E.F. Optimal decoding of cellular identities in a genetic network. Cell 2019, 176, 844-855. [CrossRef] [PubMed]

39. Kolchinsky, A.; Wolpert, D.H. Semantic information, autonomous agency and non-equilibrium statistical physics. Interface Focus 2018, 8. [CrossRef]

40. Cárdenas-García, J.F.; Ireland, T. The fundamental problem of the science of information. Biosemiotics 2019, 12, 213-244. [CrossRef]

41. Bosancic, B.; Matijevic, M. Information as a construction. J. Librariansh. Inf. Sci. 2019. [CrossRef]

42. Chapman, D. What can we say about information? Agreeing a narrative. Proceedings 2017, 1, 49. [CrossRef]

43. Janich, P. What is Information? Hayot, E.; Pao, L., Translators; University of Minnesota Press: Minneapolis, MN, USA, 2018.

44. Hayles, N.K. How We Became Post-Human: Virtual Bodies in Cybernetics, Literature, and Informatics; University of Chicago Press: Chicago, IL, USA, 1999.

45. Groes, S. Information overload in literature. Textual Pract. 2017, 31, 1481-1508. [CrossRef]

46. Floridi, L. The Fourth Revolution: How the Infosphere is Shaping Human Reality; Oxford University Press: Oxford, UK, 2014.

47. Gorichanaz, T. Understanding and information in the work of visual artists. J. Assoc. Inf. Sci. Technol. 2019. [CrossRef]

48. Brier, S. Cybersemiotics: Why Information is not Enough; University of Toronto Press: Toronto, ON, Canada, 2008.

49. Brier, S. Cybersemiotics: An evolutionary world view going beyond entropy and information into the question of meaning. Entropy 2010, 12, 1902-1920. [CrossRef]

50. Brier, S. The transdisciplinary view of information theory from a cybersemiotic perspective. In Theories of Information, Communication and Knowledge: A Multidisciplinary Approach; Ibekwe-SanJuan, F., Dousa, T., Eds.; Springer: Dordrecht, The Netherlands, 2013; pp. 23-49.

51. Brier, S. How to produce a transdisciplinary concept for a universal theory of information. In Information Studies and the Quest of Transdisciplinarity: Unity through Diversity; Chapter 2; Burgin, M., Hofkirchner, W., Eds.; World Scientific: Singapore, 2017. [CrossRef]

52. Brenner, J.E. Information: A personal synthesis. Information 2014, 5, 134-170. [CrossRef]

53. Mingers, J.; Standing, C. What is information? Toward a theory of information as objective and veridical. J. Inf. Technol. 2018, 33, 85-104. [CrossRef]

54. Capurro, R. Past, present and future of the concept of information. Triple-C 2009, 7, 125-141. [CrossRef]

55. Bawden, D.; Robinson, L. Super-science, fundamental dimension, way of being: Library and information science in an age of messages. In Information Cultures in the Digital Age: A Festschrift in Honor of Rafael Capurro; Kelly, M., Bielby, J., Eds.; Springer: Wiesbaden, Germany, 2016; pp. 31-43.

56. Hidalgo, C. Why Information Grows: The Evolution of Order, from Atoms to Economics; Allen Lane: London, UK, 2015.

57. Popper, K.R. Objective Knowledge: An Evolutionary Approach (Revised Edition); Clarendon Press: Oxford, UK, 1979. 
58. Brookes, B.C. The foundations of information science. Part 1: Philosophical aspects. J. Inf. Sci 1980, 2, 125-133. [CrossRef]

59. Notturno, M.A. Science and the Open Society; Central European University Press: Budapest, Hungary, 2000.

60. Gnoli, C. Mentefacts as a missing level in theory of information science. J. Doc. 2018, 74, 1226-1242. [CrossRef]

61. Floridi, L. The Logic of Information: A Theory of Philosophy as Conceptual Design; Oxford University Press: Oxford, UK, 2019.

62. Gorichanaz, T.; Furner, J.; Ma, L.; Bawden, D.; Robinson, L.; Dixon, D.; Herold, K.; Obelitz Søe, S.; Van der Veer Martens, B.; Floridi, L. Information and Design: Book Symposium on Luciano Floridi's 'The Logic of Information'. J. Doc. 2020, in press. [CrossRef]

63. Burgin, M. Theory of Information: Fundamentality, Diversity and Unification; World Scientific: Singapore, 2010.

64. Floridi, L. The Philosophy of Information; Oxford University Press: Oxford, UK, 2011.

65. Floridi, L. The Ethics of Information; Oxford University Press: Oxford, UK, 2013.

66. Floridi, L. Mapping the philosophy of information. In The Routledge Handbook of the Philosophy of Information; Routledge: London, UK, 2016; pp. 1-3.

67. Walton, P. A model for information. Information 2014, 5, 479-507. [CrossRef]

68. Walton, P. Measures of information. Information 2015, 6, 23-48. [CrossRef]

69. Walton, P. Information and meaning. Information 2016, 7, 41. [CrossRef]

70. Burgin, M. Information theory: A multifaceted model of information. Entropy 2003, 5, 146-160. [CrossRef]

71. Burgin, M. Foundations of information theory. arXiv 2008, arXiv:0808.0768v1[cs.IT].

72. Burgin, M. The General Theory of Information as a unifying factor for information studies: The noble eight-fold path. Proceedings 2017, 1, 164-169. [CrossRef]

73. Burgin, M. Evolutionary information theory. Information 2013, 4, 124-168. [CrossRef]

74. Burgin, M.; Feistel, R. Structural and symbolic information in the context of the General Theory of Information. Information 2017, 8, 139. [CrossRef]

75. Brenner, J.E. Mark Burgin's Theory of Information. Information 2012, 3, 224-228. [CrossRef]

76. Burgin, M.; Feistel, R. Structures and structural information. Proceedings 2017, 1, 217-221. [CrossRef]

77. Feistel, R.; Ebeling, W. Entropy and the self-organization of information and value. Entropy 2016, $18,193$. [CrossRef]

78. Burgin, M. Data, Information, and Knowledge. 2004. Available online: https://www.math.ucla.edu/ $\sim\{\}$ mburgin/papers/knowinfpp2.pdf (accessed on 28 January 2020).

79. Burgin, M.; Dodig-Crnkovic, G. Prolegomena to information taxonomy. Proceedings 2017, 1, $210-214$. [CrossRef]

80. Brenner, J.E. Three aspects of information science in reality: Symmetry, semiotics and society. Information 2015, 6, 750-772. [CrossRef]

81. Brenner, J.E. Philosophy of information: Revolution in philosophy. Proceedings 2017, 1, 101. [CrossRef]

82. Wu, K.; Brenner, J. Philosophy of information: Revolution in philosophy. Towards an informational metaphilosophy of science. Philosophies 2017, 2, 22. [CrossRef]

83. Brenner, J.E. The logical dynamics of information: Deacon's "Incomplete Nature". Information 2012, 3, 676-714. [CrossRef]

84. Brenner, J.E. The logic of the physics of information. Information 2014, 5, 389-403. [CrossRef]

85. Brenner, J.E. Levels of abstraction; levels of reality. In Luciano Floridi's Philosophy of Technology: Critical Reflections; Demir, H., Ed.; Springer: Dordrecht, The Netherlands, 2012; pp. 201-222.

86. Floridi, L. The road to the Philosophy of Information. In Luciano Floridi's Philosophy of Technology: Critical Reflections; Demir, H., Ed.; Springer: Dordrecht, The Netherlands, 2012; pp. 245-271.

87. Hofkirchner, W. How to achieve a unified theory of information. Triple-C 2009, 7, 357-368. [CrossRef]

88. Hofkirchner, W. Toward a new science of information. Information 2010, 2, 372-382. [CrossRef]

89. Hofkirchner, W. Twenty Questions about a Unified Theory of Information; Emergent Publications: Litchfield Park, AZ, USA, 2010.

90. Hofkirchner, W. Emergent Information: A Unified Theory of Information Framework; World Scientific: Singapore, 2013.

91. Bawden, D. Organised complexity, meaning and understanding: An approach to a unified view of information for information science. Aslib Proc. 2007, 59, 307-327. [CrossRef]

92. Stonier, T. Information and the Internal Structure of the Universe; Springer: Berlin, Germany, 1990. 
93. Stonier, T. Beyond Information: The Natural History of Intelligence; Springer: Berlin, Germany, 1992.

94. Stonier, T. Information and Meaning: An Evolutionary Perspective; Springer: Berlin, Germany, 1997.

95. Stonier, T. Towards a new theory of information. J. Inf. Sci. 1991, 17, 257-263. [CrossRef]

96. Stonier, T. Information as a basic property of the universe. Biosystems 1996, 38, 135-140. [CrossRef]

97. Morán-Reyes, A.A. Contribution to the ontological status of information: Development of the structural-attributive approach. Libr. Trends 2015, 63, 574-590. [CrossRef]

98. Bates, M.J. Information and knowledge: An evolutionary framework for information. Inf. Res. 2005, 10, 239.

99. Bates, M.J. Fundamental forms of information. J. Am. Soc. Inf. Sci. Technol. 2006, 57, 1033-1045. [CrossRef]

100. Goonatilake, S. The Evolution of Information: Lineages in Gene, Culture and Artefact; Pinter Publishers: London, UK, 1991.

101. Madden, D. Evolution and information. J. Doc. 2004, 60, 9-23. [CrossRef]

102. Floridi, L. Information - A Very Short Introduction; Oxford University Press: Oxford, UK, 2010.

103. Capurro, R. On Floridi's metaphysical foundation of information ecology. Ethics Inf. Technol. 2008, 10, 167-173. [CrossRef]

104. Compton, B.W. Parallax ontology and the philosophy of information. Libr. Trends 2015, 63, 555-573. [CrossRef]

105. Adams, F.; de Moraes, J.A. Is there a philosophy of information? Topoi 2016, 35, 161-171. [CrossRef]

106. Floridi, L. On human dignity as a foundation for the right to privacy. Philos. Technol. 2016, 29, 307-312. [CrossRef]

107. Floridi, L.; Taddeo, M. What is data ethics? Philos. Trans. R. Soc. A 2016. [CrossRef]

108. Mittelstadt, B.D.; Floridi, L. The ethics of big data: Current and foreseeable issues in biomedical contexts. Sci. Eng. Ethics 2016, 22, 303-341. [CrossRef]

109. Floridi, L. Soft ethics, the governance of the digital and the General Data Protection Regulation. Philos. Trans. R. Soc. A 2018. [CrossRef] [PubMed]

110. Floridi, L.; Cowls, J. A unified framework of five principles for AI in society. Harv. Data Sci. Rev. $2019,1$. [CrossRef]

111. Floridi, L. The green and the blue: Naïve ideas to improve politics in a mature information society. In The 2018 Yearbook of the Digital Ethics Lab; Springer: Cham, Switzerland, 2019; pp. 183-221.

112. Bawden, D.; Robinson, L. Curating the infosphere: Luciano Floridi's Philosophy of Information as the foundation for Library and Information Science. J. Doc. 2018, 74, 2-17. [CrossRef]

113. Dinneen, J.D.; Brauner, C. Practical and philosophical considerations for defining information as well-formed, meaningful data in the information sciences. Libr. Trends 2015, 68, 378-400. [CrossRef]

114. Fyffe, R. The value of information: Normativity, epistemology, and LIS in Luciano Floridi. portal Libr. Acad. 2015, 15, 267-286. [CrossRef]

115. Van der Veer Martens, B. An illustrated introduction to the infosphere. Libr. Trends 2015, 63, 317-361. [CrossRef]

116. Van der Veer Martens, B. New grounds for ontic trust: Information objects and LIS. Educ. Inf. 2017, 33, 37-54. [CrossRef]

117. Ward Bynum, T. On the possibility of quantum informational structural realism. Minds Mach. 2013, 24, 123-139. [CrossRef]

118. Ward Bynum, T. Informational metaphysics. In The Routledge Handbook of the Philosophy of Information; Floridi, L., Ed.; Routledge: London, UK, 2016; pp. 203-218.

119. Floridi, L. The method of levels of abstraction. Minds Mach. 2008, 18, 303-329. [CrossRef]

120. Floridi, L. The method of abstraction. In The Routledge Handbook of the Philosophy of Information; Floridi, L., Ed.; Routledge: London, UK, 2016; pp. 50-56.

121. Chapman, D. Information in layers. Proceedings 2017, 1. [CrossRef]

122. Floridi, L. What is a philosophical question? Metaphilosophy 2013, 44, 195-221. [CrossRef]

(C) 2020 by the authors. Licensee MDPI, Basel, Switzerland. This article is an open access article distributed under the terms and conditions of the Creative Commons Attribution (CC BY) license (http://creativecommons.org/licenses/by/4.0/). 